\title{
DESIGNING PRECINCTS IN THE DENSIFYING CITY - THE ROLE OF PLANNING SUPPORT SYSTEMS
}

\author{
O. Gudes ${ }^{1, *}$, S. Glackin ${ }^{2}$, C. Pettit ${ }^{1}$ \\ ${ }^{1}$ City Futures, University of New South Wales - (o.gudes, c.pettit)@unsw.edu.au \\ ${ }^{2}$ Centre for Urban Transitions, Swinburne University of Technology - (sglackin@ swin.edu.au)
}

KEY WORDS: Data-driven approaches; Geographic Information Systems (GIS); Collaborative planning; Medium density; Digitalplanning tools.

\begin{abstract}
:
Australia's cities face significant social, economic and environmental challenges, driven by population growth and rapid urbanisation. The pressure to increase housing availability will lead to greater levels of high-density and medium-density stock. However, there is enormous political and community pushback against this. One way to address this challenge is to encourage medium-density living solutions through "precinct" scale development. Precinct-scale development has the potential to include additional hard and soft infrastructure that may offset the perceived negativities of higher densities. As part of Australian research into precinct-scale development, and as part of our broader Smart Cities approach, or more specifically City Analytics approach, new digital planning tools - Envision and ESP - have been developed to support scenario planning and design needs. They utilise a datadriven and scenario planning approach underpinned by Geographic Information System (GIS) functionality.

We focus on a case study in the City of Blacktown, Western Sydney, New South Wales, Australia. By 2036 Blacktown is forecast to grow to approximately 500,000 people (an increase of over 30\%) and 180,000 dwellings. Most new dwellings will be delivered through urban infill. The Blacktown master plan promotes higher density housing, mixed employment uses and continued improvements to the public domain. Our study provides a unique opportunity to implement this broad strategy within a specific case and location. Specifically, this paper provides information on how these digital planning tools supported Blacktown planners in identifying, co-designing and implementing a new approach for precinct level planning. It also presents the results of an evaluation of digital-planning tools in the context of the Blacktown case study.
\end{abstract}

\footnotetext{
* Corresponding author
} 


\section{INTRODUCTION}

Australia's cities face significant pressures due to rapid urbanisation and population growth. One of the challenges arising from growing housing demand is the need to plan for both high- and medium-density living. Given these pressures, Australia's cities are now challenged by a critical need for smarter frameworks, methods and analytical tools to assist planners to work more effectively with communities to instigate sustainable city development (Pettit et al., 2018). This research focuses on a case study undertaken in the City of Blacktown, Western Sydney, New South Wales, Australia. It concerns the use and adoption of data-driven tools, such as Envision (Newton and Glackin, 2014) and Envision Scenario Planner (ESP) (Trubka et al., 2016), which have been developed and applied in the Australian and New Zealand contexts. The authors also discuss the use of the CityData Store (Leao et al., 2017), which is a geospatial data store that supports data sharing between researchers, planners and potentially the Blacktown community. The CityData Store serves as a platform for the publication of open city data to the community and supports a distributed research environment. Practically, this research employs a data-driven collaborative-planning approach, using GIS data and digital-planning tools (DPTs), which are interchangeably referred to as planning support systems (PSS) (Pettit et al., 2018) and underpinned by the emerging discipline known as Planning Support Science (Geertman et al., 2017). PSS are employed to enhance a working partnership with local planners and the community. It is envisaged that the development of a conceptual-planning framework with the support of PSS such as Envision and ESP, will effectively connect planners, policy-makers, practitioners, researchers and communities to collectively plan more sustainable, productive and resilient urban futures.

In an era of open data, city data is increasingly being made available to planners and the urban-research community through government open platforms and e-research infrastructure (Glackin \& Gudes, 2017). Furthermore, with the move away from lot-by-lot redevelopment approaches and toward precinct-scale development approaches, we believe that new planning opportunities will be created. This will promote the development of new conceptual frameworks and planning models that can equip the next generation of planners to make cities more sustainable, productive and resilient.

\subsection{The Australian context}

Suburbanisation was, as with many cities globally, the dominant planning trend for the second half of the twentieth century. However, due to the relative newness of Australian cities, there was little in the way of an established culture of medium- or high-density living, as existed in older, European style cities. So, the move to the suburbs not only created a norm of detached houses on large blocks, it also (due to the lack of alternatives) cemented this form of dwelling as the only type of "real" dwelling. This celebration of the single house on a large lot became mythicised locally as the core feature of "the Great Australian Dream", a nation-building exercise suggesting that all individuals crave a single house on a large lot of suburban land. And again, as with other cities globally, the ramifications of normalised suburbanisation led to vast tracts of almost exclusively residential land, characterised by car dependency.

Unlike the European suburban pattern, where suburban subdivisions generally occur in terraced "blocks" or rows of semi-detached housing, the typical Australian suburban subdivision pattern accommodates single, free-standing dwellings, leading to subdivision (See also Figure 1).

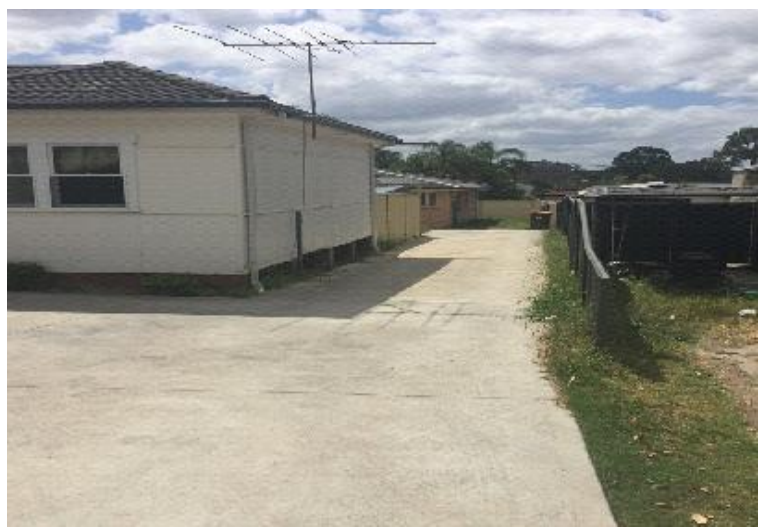

Figure 1. An example of subdivision (granny flat at the rear side of the lot) in Blacktown, NSW

The product of these subdivisions creates a range of suboptimum outcomes. The most obvious is the increase in housing density. While this is not necessarily an issue in terms of sustainable outcomes, in that housing agglomeration is notably beneficial for the environment (Trubka et al., 2010a, 2010b, 2010c), it does place increasing pressure on surrounding infrastructure, particularly when the scale of redevelopment is considered (Newton et al., 2017). This is particularly problematic when we consider that there is no new additional space for additional resources. This, in turn, results in increasing demand for more land, administration and funding than is achievable with lot-by-lot redevelopment style.

Linked to housing density is the amount of land given over to driveways, access and parking. The amount of land provided for vehicles in the current subdivision environment is unsustainable (typically 25-40\% of subdivision land - from Authors' calculations). Apart from being an inefficient use of land, this also reduces the amount of private open space and potential tree canopy, as large trees are removed to provide space for dwellings (Witheridge, 2015). All of this, combined with the additional roofing and building footprint, drastically reduces the amount of permeable soil and vegetative uptake of groundwater, leading to a significant increase in overland storm water flow (Hogue et al., 2017). Additionally, this form of redevelopment is having a pronounced impact on Urban Heat Island (UHI) effect.

\subsection{Greyfields and lot amalgamation}

Newton (2010) proposed a solution to these issues by promoting regeneration "precincts", or larger redevelopment on amalgamated lots, as an alternative to the dominant lot-by-lot form of redevelopment. Though more complex, particularly in relation to the forms of agreement needed between landowners, if it could be done, precincts could optimise the land use. Through economies of scale and a higher degree of planning than lot-by-lot development allows, precinct developments could achieve vastly superior outcomes, especially, in terms of sustainable design, walkability and infrastructure provision. Initial research in the area proved the macro-economic feasibility of the concept, illustrating how land agglomeration could positively affect a range of financial, sustainability and 
liveability indicators (Glackin et al., 2016). On a precinct scale, lot amalgamation has been shown to achieve significant financial benefits for property owners. Individual parcel consolidation into "super lots" has seen individuals make considerably higher returns on their land than if it were sold individually. This is due to the scale of development that can occur on larger lots, due to (among other factors) relaxation of height and setback regulations due to the larger buffers that developments on larger lots can place around them. Land can be further optimised by significantly reducing the land required for driveways, turning circles and parking, which, as illustrated in Figure 2, utilises significant proportions of redeveloped land in the business as usual scenario.

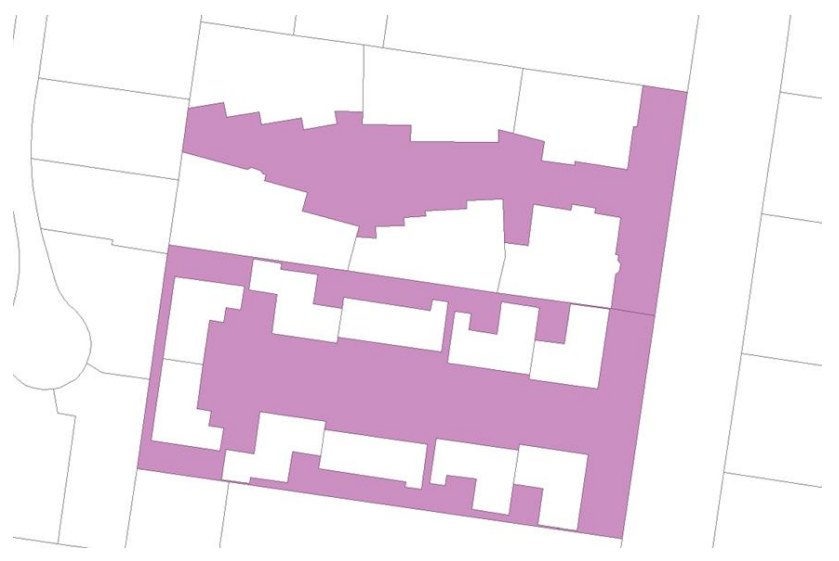

Figure 2. Subdivisions using $45-55 \%$ of available land for parking and turning circles

With the significant financial gains that landowners and developers aim to make, there is also the possibility of further altering the limitations on development. This will allow developers to earn even more yield, if they satisfy specific criteria set by the governing body (a municipal government, in the Australian context). By exploring the needs of a specific community, a municipality can suggest a set of precinct "additionalities" that, if they choose, developers can implement, and for which they will gain further development concessions. This is effectively a value capture mechanism, where the municipality can advance some of its policies, in the context of the specific locality, through the development of new precincts.

Our approach to precinct-scale development (i.e. 4 to 40 or more land parcels) aimed to redevelop aging housing stock in Australian suburbs (Glackin and Gudes, 2017). The rationale was that the middle suburbs of Australian cities are going through lot-by-lot redevelopment with little strategic oversight or direction. However, with policy intervention from strategic planners, these lots could provide far more dwellings and far greater social and environmental ecological benefits if they were developed as amalgamated lots (precincts), rather than individually (Glackin and Gudes, 2017).

While this planning scheme is theoretically possible, there is no existing land use tool to allow for significant changes to the planned land-use outcomes, based on providing additional benefit to the municipality and community. This is currently being addressed in Australia. Following the adoption of the new planning scheme, we will then commence the community engagement process to promote this new planning scheme. However, all the above could not have been achieved without the aid of PSS.

\subsection{Planning support systems (PSS)}

Planning support systems are computer-based tools that add value to the planner's work processes and include systems such as spreadsheets, GIS driven analytical platforms and online decision support systems. Pettit et al. (2018) provide a recent summary of the state of the art PSS that have been applied in the context of Australia, with a number of these, including What if? (Pettit et al., 2013) and CommunityViz (Lieske and Hamerlinck, 2015), having been applied internationally. We are currently seeing the maturing of PSS as useful instruments in the day-to-day urban planning practice, where the focus has previously been on technology development for planning support science (Geertman, 2013). PSS provide the opportunity to support better planning and urban data management. This is critically important to achieving sustainable, productive and resilient urban landscapes. In this research we utilise two established GIS-based PSS: (i) Envision and (ii) Envision Scenario Planner (ESP). These tools were developed to assist urban planners and decision makers in planning precinct-scale redevelopment in greyfield residential areas both to revitalise neighbourhoods and to encourage infill housing (Glackin et al., 2016). Envision is a web-based application that is used to indicate where capacity for future neighbourhood change is greatest (Newton and Glackin, 2013). Envision has three core tools:

1. Multi-Criteria Evaluation (MCE), which uses statistics at the Australian Bureau of Statistics' statistical area level one (SA1) scale to identify lots that meet user-defined criteria, such as the count of housing types or population by age, etc (See also Figure 3);

2. Redevelopment potential, which allows the user to define parameters such as 'distance from major roads' or 'distance to train station' and will identify lots that meet these parameters in addition to including or excluding properties that have constraints such as 'environmental management', 'sensitive areas' or 'heritage protected sites';

3. Viability assessment, which provides a simple summary of the potential redevelopment outcomes of a user-defined precinct, including variables such as housing typology and quality.

Envision can provide the basis for creating a framework for municipal governments to designate future development scenarios for more intensified levels of neighbourhood change and regeneration. Envision can be used to identify specific land parcels that have potential for redevelopment, and to assess the economic viability of a potential redevelopment. Additionally, Envision enables a data-driven approach and a less subjective method of identifying precincts that have potential for redevelopment. When a precinct has been identified in Envision, a user can export the property boundaries in a spatial data or GIS format that can be imported into ESP, meaning the two tools are easily integrated (Glackin, 2013). ESP has recently been redeveloped as part of the Australia and New Zealand Cooperative Research Centre for Spatial Information's (CRC-SI) Greening the Greyfields study. 


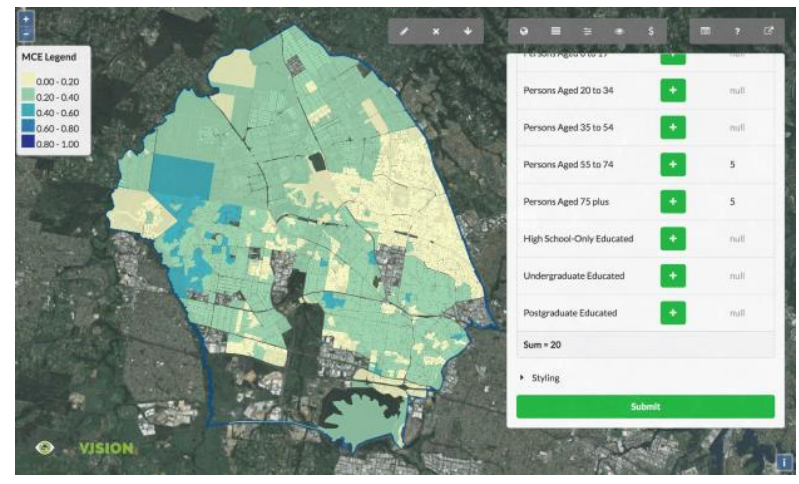

Figure 3. Envision MCE tool

ESP is a web-based system for precinct design, visualisation and assessment; its specifications were determined by conducting workshops with stakeholders, industry experts and potential end users in Western Australia and Victoria (Pettit et al., 2014; Trubka et al., 2016). Basic requirements for the system included the positioning and visualisation of threedimensional (3D) models / objects of representative dwelling typologies and an assessment framework and logic for generating feedback on a series of sustainability indicators. Users of ESP can easily re-zone, subdivide and amalgamate land parcels, create new lots and create and allocate various building typologies. Once a scenario has been developed, it can be assessed in a comprehensive report and compared with other scenarios' results as to their environmental and socio-economic impacts. The main goal of ESP is to enable the assessment of sustainability and liveability aspects, raising awareness of the potential impacts and benefits across different regeneration scenarios. (A demo developed by the CRC-SI of ESP tool is available here.) Together, the two tools, Envision and ESP, provide a workflow from exploration of an area in terms of demographics and precinct redevelopment potential through to specific redevelopment scenario outcomes. Figure 4 presents an example design scenario that was developed by our study participants in Blacktown using ESP; high buildings represent higher density and vice versa.

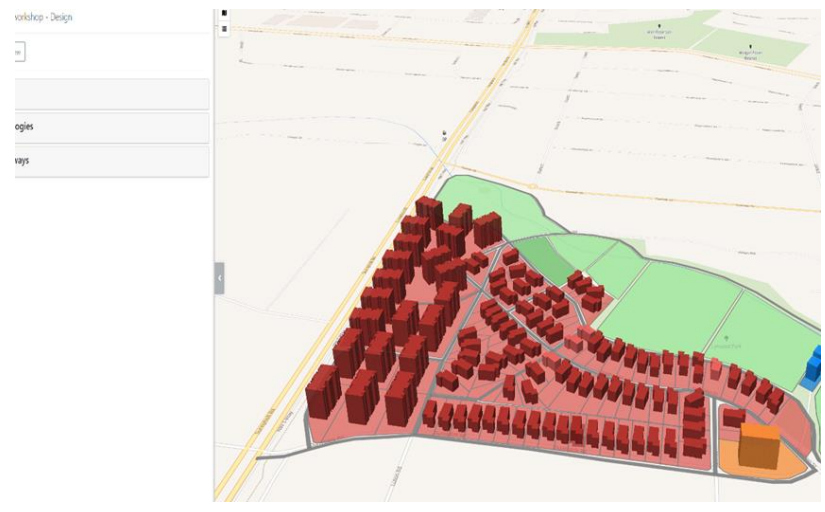

Figure 4. Design scenario for Blacktown City that was developed using ESP

\section{METHODS}

Sixty percent of all new dwellings will be built in established urban areas (greyfields). However, the addition of new dwellings is often ad hoc, with the subdivision of already existing small lots or the addition of second dwellings (known as "granny flats" in Australia) in backyards. This is an inefficient use of land and space, which often reduces existing canopy and creates traffic problems, whilst preventing higher densities. This form of development is typical for suburban municipalities, such as the City of Blacktown, New South Wales, Australia. Sydney's city centre has experienced a significant inflow of people in the last few decades. The rapid increase of the population has put pressure on the existing facilities in the city. The NSW Government has long sought ways to attract people to other part of the city by improving housing facilities and transport and increasing employment opportunities. Blacktown is the site of an urban renewal plan to create new homes and job opportunities for the growing population. According to an estimate by Blacktown City Council, the population of the City of Blacktown will increase by 160,000 by 2036 . Blacktown covers an area of 246.9 square kilometres (95.3 square miles) and had a population of 336,962 as at the 2016 census, making it the second most populous local government area (LGA) in Sydney (See also Figure 5). Blacktown is a priority area that is planned to accommodate higher densities in the future (Blacktown, 2036 plan). The 2012 Blacktown City Centre Masterplan intended to increase residential densities in the city centre urban renewal precinct and proposed specific zonings for 2036 and was one of the main reasons this location was selected as a case study.

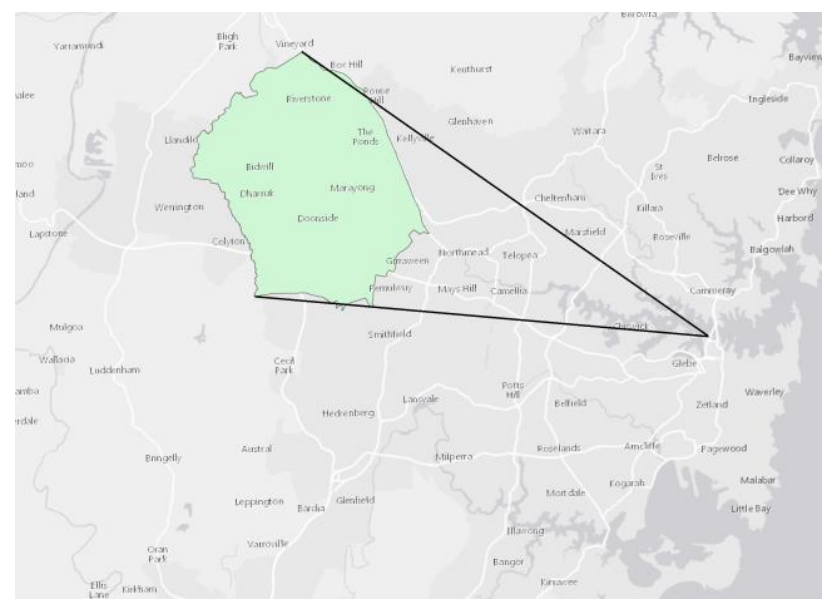

Figure 5. Blacktown area (lines indicate the location of Sydney CBD)

Previous studies by Glackin and Gudes (2017), indicated the need for deep engagement across all stakeholder groups and for "Full Stack" vertical integration of all stakeholder groups (Glackin and Gudes, 2017). This led to the development of a formal workflow or "road map" for the City of Blacktown. We distinguish between the methodological approach of the study which is focused on the evaluation of PSS, and the project workflow which is focused on the range and order of activities taken in Blacktown; these are two separate components of the study that are intertwined.

\subsection{Study workflow}

The study workflow started with initial engagement activities across the local government and state government to find a suitable case study and obtain support. For example, we organised several workshops in Blacktown with a range of stakeholders, so we could learn what are the areas of priority and learn from different perspectives. At the next stage, our PSS 
were populated with geospatial and other required data with support from the local GIS specialist from Blacktown. Table 1 lists some of the data items incorporated in our PSS.

\begin{tabular}{|l|}
\hline \multicolumn{1}{|c|}{ Item name } \\
\hline Land use \\
\hline Vacancy of land \\
\hline Population \\
\hline Density \\
\hline $\begin{array}{l}\text { Distance of each parcel from school, main road, train } \\
\text { station, shopping centre and Blacktown CBD }\end{array}$ \\
\hline Ownerships (state or private) \\
\hline Mortgage \\
\hline Rent \\
\hline Age categories \\
\hline Sales data based on unit, town house or a house \\
\hline Education data \\
\hline Socioeconomic data \\
\hline Demolition \\
\hline Heritage sites \\
\hline Environmentally sensitive areas \\
\hline
\end{tabular}

Table 1. An example of dataset items which were included in the PSS

Following this stage, the specific location for the study was selected. This location was comprehensively analysed by conducting site analysis exercises which fed into the next stage, where feedback was sought from the local government stakeholders on possible precinct design scenarios (See Figure 6). A group of participants convened to discuss future design scenarios in our study in Blacktown. Two subgroups worked simultaneously on design scenarios: one of the groups used (on the fly) the ESP tool as part of their design work (See Figure 4). The other group used a paper-based canvas to draw their design ideas in a more traditional way. There were, overall, fourteen participants, with seven participants in each group. Among them were strategic planners, social planners and architects from the City of Blacktown. For the next step, to assess the viability of the project and provide a better understanding of what could be offered to landowners and developers in terms of developmental incentives, a feasibility model will be developed (this is where our current study stands). In the next stages, we are planning to develop a community engagement plan. This, in turn will be followed by long-term implementation of the project in Blacktown, as well as a second round of PSS evaluations. Specifically, the PSS evaluation stages are derived from studies conducted by Russo et al. (2018a, 2018b). In this study we have focused on evaluating the tool's usefulness and effectiveness.

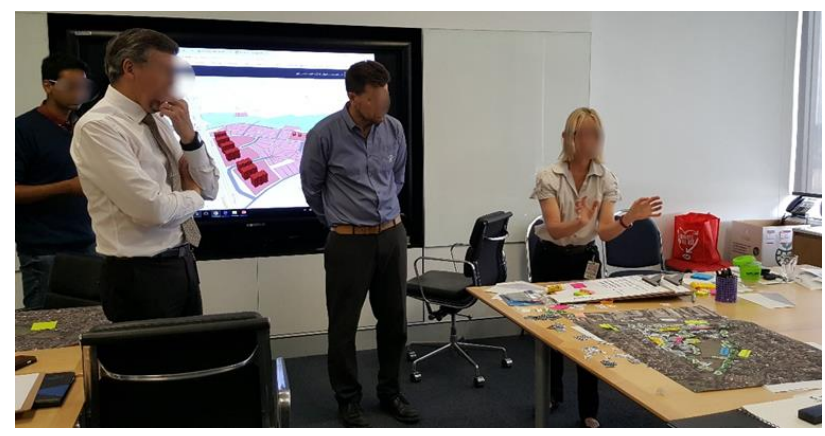

Figure 6. PSS used in designing scenarios at Blacktown, NSW

\subsection{Evaluation study of PSS}

To evaluate the impact of PSS, an evaluation study has been designed. In parallel processes, PSS were developed and tested. To evaluate the usefulness and effectiveness of the tools, we designed a pre and post online questionnaire. Two waves of data collection were planned, one prior to the proposed site design and one following design completion. Currently, we have conducted only the first wave of data collection. During February 2018 the project team delivered a training session on the specific PSS. Upon completion of the training, an evaluation questionnaire was circulated which sought input from end users. The evaluation focused on the usefulness and usability of the tools in the context of a future precinct scenario planning exercise. The next section provides some insights into our findings.

\section{RESULTS}

This section provides more information about the views that decision makers in Blacktown expressed on the level of usability and efficiency of the tools in their planning practice. For example, participants reflected on the ways PSS provided insight or supported them. The findings were based on an online questionnaire using Google Docs; overall there were seven participants. Figures 7 and 8 and Table 2 present the main findings from the evaluation survey. The findings helped us to understand which PSS measures were rated the highest by participants in terms of their importance and to then compare these measures with their performance rating. The findings indicated that the most important items (See Figure 7) are the updates, currency and flexibility of the data. This was also reflected as the highest performance indicator in Figure 8.

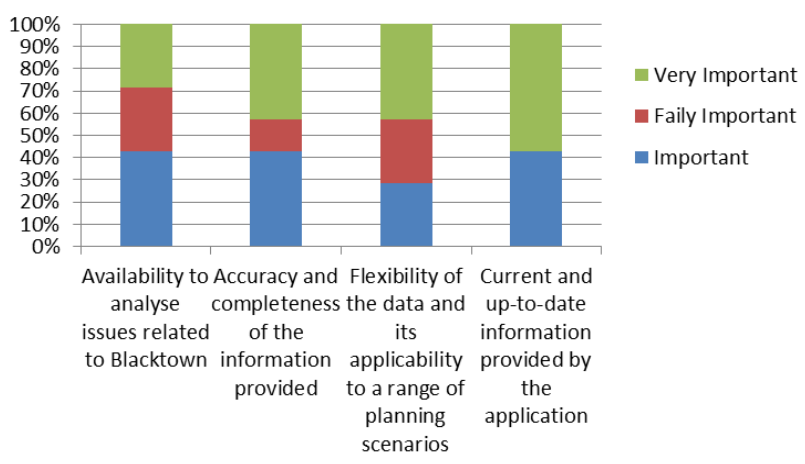

Figure 7. Importance rating of PSS measures in the Blacktown study 


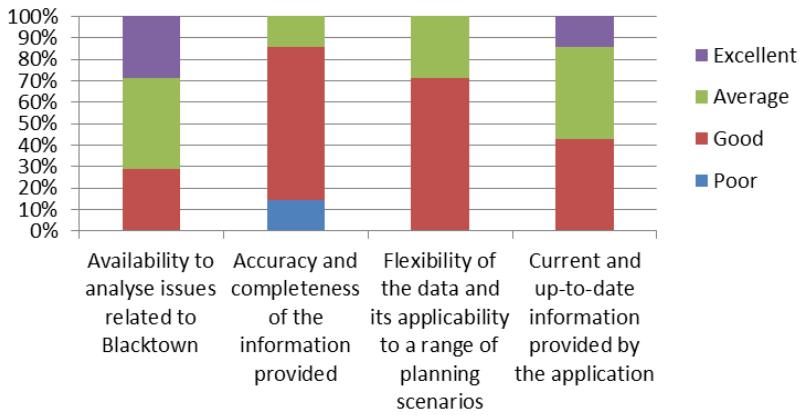

Figure 8. Performance rating of PSS measures in the Blacktown study

To provide context for the quantitative findings derived from the online questionnaire, participants were also requested to comment with their own words on their experiences. Table 2 provides important information and specific feedback about their experiences while using PSS. This allowed an evaluation of the implementation process and was also useful information and feedback to improve PSS through a co-design approach, like that conducted by Pettit et al. (2014).

\begin{tabular}{|l|ll|}
\hline $\begin{array}{l}\text { What were the } \\
\text { most useful } \\
\text { features of }\end{array}$ & - & $\begin{array}{l}\text { 3D modelling. } \\
\text { PSS? }\end{array}$ \\
& - & $\begin{array}{l}\text { Ability to abplity feature. } \\
\text { constraints and criteria. }\end{array}$ \\
& $\begin{array}{l}\text { Ability to customise the } \\
\text { scenarios. }\end{array}$ \\
\hline
\end{tabular}

\begin{tabular}{|c|c|}
\hline $\begin{array}{l}\text { What were your } \\
\text { most relevant } \\
\text { experiences } \\
\text { while engaging } \\
\text { with PSS? }\end{array}$ & $\begin{array}{l}\text { - Slowness of the system. } \\
\text { Ability to create typologies and } \\
\text { to place different 3D buildings } \\
\text { onto existing lots. } \\
\text { Using and understanding how } \\
\text { viability works. } \\
\text { The visual display of the spatial } \\
\text { information results (i.e. map } \\
\text { output generated). } \\
\text { Being able to use the different } \\
\text { criteria [for] the required } \\
\text { scenario. } \\
\text { The ability to select quickly } \\
\text { what is needed based on the } \\
\text { criteria and visualize the output } \\
\text { in [the] thematic map. } \\
\text { Data analysis using various } \\
\text { factors. }\end{array}$ \\
\hline
\end{tabular}

\begin{tabular}{|l|ll|}
\hline $\begin{array}{l}\text { List your } \\
\text { positive } \\
\text { experiences } \\
\text { using PSS }\end{array}$ & - & $\begin{array}{l}\text { 3D modelling. } \\
\text { The ease with which you can } \\
\text { place buildings in existing } \\
\text { context. }\end{array}$ \\
& - $\begin{array}{l}\text { Using and understanding the } \\
\text { [various] applications. } \\
\text { Relatively easy to use and follow } \\
\text { the tutorial steps to learn this } \\
\text { highly complex tool. }\end{array}$ \\
\hline - & $\begin{array}{l}\text { Seeing the final plan and data to } \\
\text { make planning decisions. } \\
\text { Planners visualize [how] their } \\
\text { planning works. }\end{array}$ \\
\hline List your & - & The speed of the application, too \\
\hline
\end{tabular}

\begin{tabular}{|l|l|}
\hline $\begin{array}{l}\text { negative } \\
\text { experiences or } \\
\text { limitations of } \\
\text { using PSS }\end{array}$ & $\begin{array}{l}\text { slow. } \\
\text { Not so sure the demographic } \\
\text { info is up to date and correct. } \\
\text { The individual steps are often } \\
\text { complicated. } \\
\text { Very complex and somewhat } \\
\text { hard for a non-town planner to } \\
\text { follow the scenario building and } \\
\text { modelling. } \\
\text { The application seemed to be a } \\
\text { bit slow ... to download and } \\
\text { open data for viewing } \\
\text { There [are] no measurement } \\
\text { tools to take in splitting the } \\
\text { polygon for instance, or to know } \\
\text { the area of the subject site in } \\
\text { sqm. } \\
\text { Response processing speed. }\end{array}$ \\
\hline
\end{tabular}

\begin{tabular}{|c|c|}
\hline $\begin{array}{l}\text { General } \\
\text { comments by } \\
\text { respondents }\end{array}$ & $\begin{array}{l}\text { Further work on building } \\
\text { typologies will improve the } \\
\text { functionality of the system. } \\
\text { This is very impressive, and I } \\
\text { hope I will have time to get } \\
\text { more comfortable using the } \\
\text { program. } \\
\text { It can be a very useful tool. For } \\
\text { it to become useable, it needs to } \\
\text { be current and accurate to be } \\
\text { able to argue for an outcome. } \\
\text { I think it will be very good if the } \\
\text { elevation of the terrain (or TIN) } \\
\text { can be used in selection criteria } \\
\text { to know how steep the subject } \\
\text { site is. } \\
\text { Great work!! Need a bit of work } \\
\text { to improve features. } \\
\text { Slide bar (it's not clear what we } \\
\text { are choosing. e.g. Min and Max } \\
\text { should have different colour). }\end{array}$ \\
\hline
\end{tabular}

Table 2. PSS qualitative data based on the online questionnaire

The next section presents our conclusions from the initial evaluation phase.

\section{DISCUSSION}

In summary, the findings indicate that participants appreciated the capability of the tools to present future typologies, 3D models and buildings to communicate what a future precinct may look like. In addition, positive comments were received in relation to the MCE tool provided by Envision. This was valuable feedback as the research team is constantly maintaining the data and improving its functionality. The findings from the evaluation study suggest that a shift in the way planning decisions can be made is achievable, especially by designing the appropriate tools and maintaining input datasets. As found by Russo et al. (2018a, 2018b), the delivery of comprehensive training is critical in the development and successful implementation of PSS in practice. Feedback on the practical training of planners in using PSS was positive and has assisted in gaining support for the wider adoption of these tools across the Blacktown municipality. The study introduced the 
use of PSS in developing a precinct-level plan and evaluates its role. Traditionally, once PSS had been developed, they were not assessed in terms of their effectiveness and usefulness for planners. However, evaluation is very important to ensure that such tools are not only being used appropriately, but also provide real value to planning processes and decision-making. This is a novel approach that has not been implemented in previous studies.

However, three limitations were observed while conducting this study. First, prior to this study urban planners had been told only 'what' they should develop (e.g. sustainable communities, higher density). However, they were not equipped with practical tools to support scenario explorations of 'how' to achieve these development goals. Second, a larger number of responses to the user satisfaction survey (greater than seven participants) would have increased the credibility of our online questionnaire. Third, the findings of this study need to be validated through further evaluation surveys with more participants. This is planned for in the next phase of the research.

Some recommendations for further research are also proposed. First, it would be beneficial to evaluate the PSS in the longer term and clarify whether they could achieve a positive impact not only with respect to utility and usability from the perspective of council planners and decision-makers, but also by testing their ability to facilitate collaborative planning at a broader level which includes the community. Thus, one of the potential research directions of this study is to further apply the PSS working with the local community to effect change in precinct planning. Also, there is an intention to expand the data sets as much as possible to improve the utility of the PSS. Furthermore, the PSS should be further refined for different projects, locations, governments, scopes and communities. The study provides insights and a solid basis for urban planners to improve their practice through the implementation of PSS. The research presented here builds upon previous PSS evaluation work undertaken by Vonk et al. (2005), Russo et al. (2018a, 2018b) and others.

It is anticipated that, as we live in an era of smart cities and big data, such PSS will become a pillar on which decision-makers can base informed city planning and design. Therefore, as part of our broader Smart Cities approach, new digital planning tools such as Envision, and ESP have been developed.

It is recommended that all PSS exercises should be accompanied by a robust evaluation mechanism to continually support their evolution through providing valuable feedback to improve their effectiveness and usefulness. This, in turn, may provide a solid basis for urban planners to improve their practice, especially in the domain of data-driven precinct-scale development.

\section{ACKNOWLEDGMENTS}

We gratefully acknowledge the funding and commitment to this research of the Cooperative Research Centre for Spatial Information, the Cooperative Research Centre for Low Carbon Living, the New South Wales Office of Environment and Heritage, and Blacktown City Council.

This research is funded by the CRC for Low Carbon Living Ltd supported by the Cooperative Research Centres program, an Australian Government initiative (C) [2018] Cooperative Research for Low Carbon Living
This work has been supported by the Cooperative Research Centre for Spatial Information, whose activities are funded by the Business Cooperative Research Centres Programme.

\section{Disclaimer}

Any opinions expressed in this document are those of the authors. They do not purport to reflect the opinions or views of the CRCLCL or its partners, agents or employees.

The CRCLCL gives no warranty or assurance, and makes no representation as to the accuracy or reliability of any information or advice contained in this document, or that it is suitable for any intended use. The CRCLCL, its partners, agents and employees, disclaim any and all liability for any errors or omissions or in respect of anything or the consequences of anything done or omitted to be done in reliance upon the whole or any part of this document.

This work has also been supported by the Cooperative Research Centre for Spatial Information, whose activities are funded by the Business Cooperative Research Centres Programme.

\section{REFERENCES}

Blacktown City Council. Blacktown Planning Strategy 2036 https://www.blacktown.nsw.gov.au/Home (5 May 2018).

Geertman, S., Allan, A., Pettit, C., and Stillwell, J., 2017. Introduction to 'Planning Support Science for Smarter Urban Futures'. In: Planning Support Science for Smarter Urban Futures. Springer, London, pp. 1-19.

Geertman, S., Toppen, F., and Stillwell, J. 2013., Planning Support Systems for Sustainable Urban Development. Springer, London.

Glackin, S., 2013. Redeveloping the Greyfields with ENVISION: Using participatory support systems to reduce urban sprawl in Australia, European Journal of Geography, 3(1), pp. 6-22.

Glackin, S. and Dionisio, M.R., 2016. 'Deep engagement' and urban regeneration: Tea, trust, and the quest for co-design at precinct scale, Land Use Policy, 52(Mar), pp. 363-373.

Glackin, S. and Gudes, O., 2017. Full-stack engagement: vertical integration and process precursors that promote bottomup urban transformation. State of Australian Cities Conference, Adelaide, South Australia, 28-30 November 2017.

GRASS Development Team, 2015. Geographic Resources Analysis Support System (GRASS) Software, Version 6.4. Open Source Geospatial Foundation http://grass.osgeo.org (1 June 2017).

Hogue, T. S., Panos, C., McCray, J.E. and Gilliom, R., 2017. Stormwater Infrastructure at risk: Predicting the impacts of increased imperviousness due to infill development in a semiarid urban neighborhood. American Geophysical Union, Fall Meeting 2017, Dec 12.

Leao, S.Z., Lieske, S.N., Conrow, L., Doig, J., Mann, V. and Pettit, C.J., 2017. Building a national-longitudinal geospatial 
bicycling data collection from crowdsourcing. Urban Science, 1(3), 23; doi:10.3390/urbansci1030023.

Lieske, S.N. and Hamerlinck, J.D., 2015. Integrating planning support systems and multicriteria evaluation for energy facility site suitability evaluation. Journal of the Urban and Regional Information Systems Association, 26(1), pp. 13-24.

Newton, P., 2010. Beyond greenfields and brownfields: The challenge of regenerating Australia's greyfield suburbs, Built Environment, 36(1), pp. 81-104.

Newton, P., and Glackin, S., 2013. Using geo-spatial technologies as stakeholder engagement tools in urban planning and development. Built Environment, 39(4), pp. 473-501.

Newton, P. and Glackin, S., 2014. Understanding infill: Towards new policy and practice for urban regeneration in the established suburbs of Australia's cities, Urban Policy and Research, 32(2), pp. 121-143.

Newton, P., Meyer, D., and Glackin, S., 2017. Becoming urban: Exploring the transformative capacity for a suburban-to-urban transition in Australia's low-density cities, Sustainability 9, 1718 .

Russo, P., Lanzilotti, R., Costabile, M.F., and Pettit, C.J., 2018a. Towards satisfying practitioners in using Planning Support Systems. Computers, Environment and Urban Systems, 67, pp. 9-20.

Russo, P., Lanzilotti, R., Costabile, F., and Pettit, C.J., 2018b. Adoption and use of software in land use planning practice: A multiple-country study. International Journal of HumanComputer Interaction, 34, pp. 57-72.

Pettit, C.J., Bakelmun, A., Lieske, S.N., Glackin, S., Thomson, G., Shearer, H., Dia, H., and Newman, P., 2018. Planning support systems for smart cities. City, Culture and Society, 12, pp. 13-24.

Pettit, C.J., Glackin, S., Trubka, R., Ngo, T., Lade, O., Newton P., and Newman, P., 2014. A co-design prototyping approach for building a Precinct Planning Tool. Joint International Conference on Geospatial Theory, Processing, Modelling and Applications, ISPRS Technical Commission II Symposium (Volume II-2), 6-8 October, Toronto, Canada (Eds Li and Dragicevic), pp. 47-53.

Pettit, C.J., Klosterman, R.E., Nino-Ruiz, M., Widjaja, I., Tomko, M., and Sinnott, R., 2013. The online what if? Planning support system. In: Planning Support Systems for Sustainable Urban Development. Springer, London, pp. 349-362.

Trubka, R., Newman, P. and Bilsborough, D. 2010a. Costs of urban sprawl infrastructure and transport. Environment Design Guide, 83, pp. 1-6.

Trubka, R., Newman, P., and Bilsborough, D., 2010b. Costs of urban sprawl greenhouse gases. Environment Design Guide, 84, $1-16$.

Trubka, R., Newman, P., and Bilsborough, D., 2010c. Costs of urban sprawl physical activity links to healthcare costs and productivity. Environment Design Guide, 85, pp. 1-13
Trubka, R., Glackin, S., Lade, O., and Pettit, C.J., 2016. A webbased 3D visualisation and assessment system for urban precinct scenario modelling. ISPRS Journal of Photogrammetry and Remote Sensing, 117, pp. 175-186.

Vonk, G., Geertman, S., and Schot, P., 2005. Bottlenecks blocking widespread usage of planning support systems. Environment and Planning A, 37(5), pp. 909-924.

Witheridge, J., 2015. Infill development and the distribution of open space in Melbourne, State of Australian Cities Conference 2015, Gold Coast, 9-11 December. 